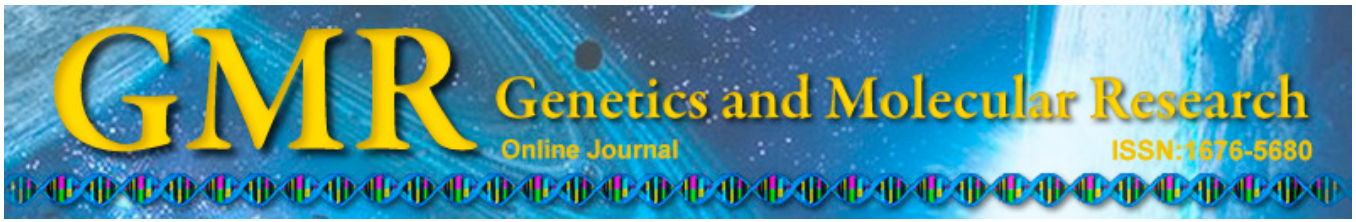

\title{
Role of fibroblast growth factor-23 in the pathogenesis of atherosclerosis in peritoneal dialysis patients
}

\author{
Y. Zeng, S. Feng, O.Y. Han, H.Y. Shen, D.H. Jin and Y.B. Shi \\ Department of Nephrology, Second Affiliated Hospital of Soochow University, \\ Suzhou, China \\ Corresponding author: Y.B. Shi \\ E-mail: su2h_syb@126.com
}

Genet. Mol. Res. 14 (1): 719-729 (2015)

Received August 2, 2013

Accepted October 5, 2014

Published January 30, 2015

DOI http://dx.doi.org/10.4238/2015.January.30.15

\begin{abstract}
Several previous studies have demonstrated that elevated levels of fibroblast growth factor-23 (FGF-23) may be involved in atherosclerosis and contribute to the high mortality rate of peritoneal dialysis (PD) patients. The aim of this study was to determine the precise role of FGF-23 in the pathogenesis of atherosclerosis in PD patients. Between April 2009 and January 2012, 62 PD patients and 25 control subjects were included in the study. An enzyme-linked immunosorbent assay was conducted to test for plasma FGF-23 levels. Carotid artery intima-media thickness (CIMT), left ventricular mass index (LVMI), and myocardial performance index (MPI) were determined by ultrasonography. Plasma $\mathrm{Ca}^{2+}, \mathrm{P}^{3+}$, calcium-phosphorus product, parathyroid hormone, $\mathrm{N}$-terminal pro-brain natriuretic peptide, and cardiac troponin I were also detected. Plasma FGF-23 levels in PD patients were significantly higher than those in control subjects. PD patients with CIMT $>1.0 \mathrm{~mm}$ showed the highest levels of FGF23. Plasma $\mathrm{P}^{3+}$, calcium-phosphorous product, plasma parathyroid hormone, CIMT, LVMI, and MPI levels were positively associated with plasma FGF-23 levels. Multiple-stepwise regression analyses
\end{abstract}


revealed that plasma $\mathrm{P}^{3+}$, plasma parathyroid hormone, CIMT, LVMI, and MPI levels were strongly associated with plasma FGF-23 levels. However, no correlations were observed in plasma N-terminal probrain natriuretic hormone and cardiac troponin I levels. Plasma FGF23 levels may play an important role in the initiation and progression of atherosclerosis. Thus, detecting and defining plasma FGF-23 levels may be a promising biomarker for the early detection of atherosclerosis in PD patients.

Key words: Atherosclerosis; Fibroblast growth factor-23; Peritoneal dialysis

\section{INTRODUCTION}

Peritoneal dialysis (PD) is now an established form of therapy for managing endstage renal failure (Oh et al., 2012). PD is well-known to have many advantages compared to hemodialysis. For example, PD allows for greater mobility during treatment, produces fewer differences in symptoms because of its continuous nature, is more effective at removal of phosphate compounds, and shows a reduction in complications associated with dialysis because of environmental instability, including imbalance syndrome, rapid changes in blood pressure, cardiac arrhythmias, and cardiac arrest, among others (Mehrotra et al., 2011; Sinnakirouchenan and Holley, 2011). However, mortality remains high in PD patients compared to non-uremic patients (Lim et al., 2011). Cardiovascular disease is the most common cause of death in PD patients worldwide (Carrero et al., 2011). The annual mortality rate in PD patients with cardiovascular complications is $15-25$-fold higher than that of nonuremic patients (Boudville et al., 2012).

Increasing evidence suggests that the increase in cardiovascular mortality in PD patients results from interactions between traditional (e.g., hypertension, dyslipidemia, diabetes) and non-traditional cardiovascular risk factors, including oxidative stress, primarily micro-inflammation, and deranged calcium phosphate metabolism because of widespread disorders in mineral metabolism (Hernandez et al., 2013). Large prospective cohort studies demonstrated that hyperphosphatemia, high parathyroid hormone (PTH), and hypovitaminosis D are independently associated with cardiovascular morbidity and mortality in PD patients (Mailliez et al., 2008; Wald et al., 2008).

Fibroblast growth factor-23 (FGF-23), a 251-amino acid protein synthesized and secreted by osteoblasts and osteocytes, is a recently discovered potent regulator of serum phosphate levels (Seiler et al., 2010; Shimada et al., 2010). FGF-23, together with its coreceptor klotho, induces renal phosphate excretion by suppressing renal $\mathrm{Na} / \mathrm{Pi}$ co-transporter activity in the proximal tubule (Prié et al., 2009). Additionally, it reduces intestinal phosphate absorption by inhibiting 25-hydroxyvitamin D3 1- $\alpha$-hydroxylase, which catalyzes the rate-determining step in calcitriol synthesis (Razzaque and Lanske, 2007). Extensive research has concluded that FGF-23 may play important roles in regulating the hyperphosphatemia, serum PTH, and 1,25-dihydroxyvitamin D3 [1,25(OH)2D3] levels (Mehrotra et al., 2009). Several previous studies have also demonstrated that FGF-23 is independently associated with several cardiovascular risk factors such as endothelial dysfunction, arterial stiffness, total body atherosclerosis in cardiovascular diseases, left 
ventricular hypertrophy (LVH), and left ventricular dilatation (Mirza et al., 2009a,b). Atherosclerosis is a very important predictor leading to the morbidity and mortality of PD patients (Malík et al., 2009).

In general, FGF-23 is negatively correlated with cholesterol and non-high-density lipoprotein; notably, formation mechanisms in atherosclerosis mainly include lipid-infiltration and endothelial injury theories, indicating that plasma FGF-23 is likely associated with the incidence of atherosclerosis development in PD patients (Ashikaga et al., 2010; Webster et al., 2013). However, there have been no previous studies examining the relationship between plasma FGF-23 levels and the development of atherosclerosis in PD patients. Therefore, we performed this study to determine the role of FGF-23 in the pathogenesis of atherosclerosis in PD patients.

\section{MATERIAL AND METHODS}

\section{Ethics statement}

The Ethics Committee of the Second Hospital Affiliated to Soochow University approved the study design. All patients signed written informed consent forms to undergo diagnostic and therapeutic procedures at the time of hospitalization.

\section{Subjects}

Between April 2009 and January 2012, PD patients admitted to the Medical Center of the Second Hospital Affiliated to Soochow University were initially selected for the study. Patients who met all of the following criteria were enrolled in this study: 1) subjects who were aged $\geq 18$ years; 2 ) patients with no history of severe infections, acute cardiovascular or cerebrovascular events, major trauma or surgery, active hepatitis, active malignancies, intravenous injection of iron, rheumatic heart disease, congenital heart disease, pulmonary heart disease, hyperthyroidism heart disease, valvular heart disease, peripheral vascular disease, active lupus without receiving hormones, or immunosuppressive therapy within 1 month. Patients who failed to meet the inclusion criteria were excluded.

A total of 62 PD patients ( 32 females and 30 males) with a mean age of $57.6 \pm 14.2$ years were included in the study. The mean duration of dialysis was $55.0 \pm 7.0$ weeks. The primary diseases in all PD patients included: chronic glomerulonephritis $(\mathrm{N}=33)$, hypertensive nephropathy $(\mathrm{N}=8)$, diabetic nephropathy $(\mathrm{N}=11)$, polycystic kidney $(\mathrm{N}=3)$, and unknown diseases $(\mathrm{N}=7)$. All PD patients were given regular dialysis treatments with a dialysis dose of 6-10 L/day using 1.5-2.5\% conventional lactate dialysis fluid and the double-pipe system (Baxter Corporation, Deerfield, IL, USA) over 6 months. In addition, 25 healthy subjects were matched for age and gender with a mean age of $52.7 \pm 13.5$ years, and were included as a control group.

\section{Experimental methods}

Five-milliliter venous blood samples were obtained in the early morning after $12 \mathrm{~h}$ of fasting and placed in a vacuum blood sample collection device containing ethylenediamine tetraacetic acid anticoagulant and mixed within 10-20 min. After centrifugation for $20 \mathrm{~min}$ at 
2000-3000 rpm (2000 g), the clear supernatant was carefully collected and stored at $-80^{\circ} \mathrm{C}$. Using an enzyme-linked immunosorbent assay, the controls and samples to be tested were added to a coating board that had been pre-coated with transparent enzyme-labeled FGF-23 monoclonal antibodies. After incubation, the unbound components were removed by washing the sample-containing coating board. Working enzyme solution was added and the unbound components were removed by washing the samples again after incubation. After adding the substrates A and B, a blue product was observed when horseradish peroxidase catalyzed conversion of the TMB substrate and turned yellow through the action of the acid. Color intensity was positively correlated with FGF-23 concentration. Optical density was measured at a wavelength of $450 \mathrm{~nm}$. Optical density values of samples were compared to standards to calculate the concentration of FGF-23 in the sample.

Carotid artery ultrasonography was performed using Philips/ATL HDI 5000 US ultrasound equipment (Philips Medical Systems, Eindhoven, Netherlands). In all PD patients, bilateral carotid artery anatomy, hemodynamics, and vascular endothelial thickness were determined. Common carotid artery intima-media thickness (CIMT) was measured $10 \mathrm{~mm}$ away from the carotid bifurcation. CIMT is defined as the vertical distance between the leading edge of the lumen-intima interface and the leading edge of the media-adventitia interface. The maximum CIMT values were then recorded, and the average value was calculated. Based on the standards of the American Heart Association, CIMT $\geq 1.0 \mathrm{~mm}$ is also known as carotid atherosclerosis.

Color Doppler ultrasonic diagnostic equipment (Vivid 7; GE Healthcare, Little Chalfont, UK) was used to determine the left ventricular systolic time, left ventricular posterior wall thickness, and left ventricular end-diastolic diameter with a probe frequency of 2.5-4.0 MHz. Left ventricular mass (LVM) and LVM index (LVMI) were calculated according to Deverux et al. (1986). All dates were measured during 3 consecutive cardiac cycles, and the mean value was obtained.

\section{Statistical analysis}

Data are reported as means \pm standard deviation (SD) or frequencies. The $\chi^{2}$ test was used to compare frequencies. One-way analysis of variance and Student $t$-tests were used for normally distributed variables, whereas the Mann-Whitney U-test was used for non-normally distributed variables. Comparisons between the 2 groups for nominal variables were made by the Fisher exact test. Relationships were evaluated using Pearson's univariate correlation analysis and by using stepwise and multiple-linear regression methods. All statistical analyses were performed using the SPSS 18.0 software (SPSS, Inc., Chicago, IL, USA). P $<0.05$ was considered to be statistically significant.

\section{RESULTS}

\section{Plasma FGF-23 levels in PD patients and healthy controls}

Plasma FGF-23 levels in PD patients was significantly higher than those in healthy controls $\left(\mathrm{P}<0.001\right.$; Figure 1). We also observed higher levels of plasma $\mathrm{Ca}^{2+}, \mathrm{P}^{3+}, \mathrm{Ca} \times \mathrm{P}$, and $\mathrm{PTH}$ in PD patients compared to those of healthy controls (all $\mathrm{P}<0.05$; Table 1). 


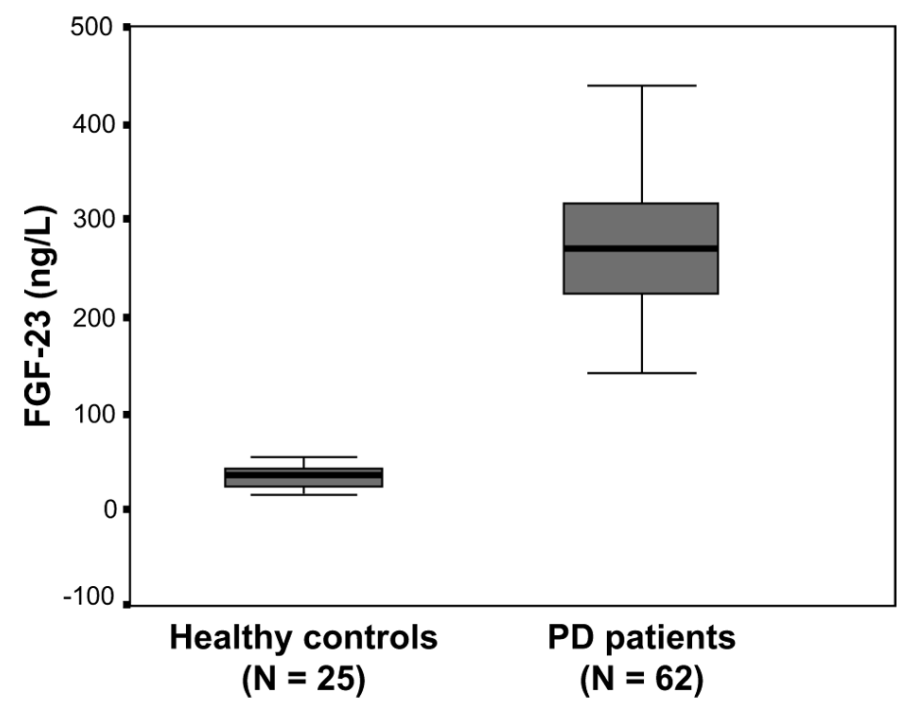

Figure 1. Comparisons of plasma FGF-23 levels between PD patients and healthy controls. FGF-23, fibroblast growth factor-23; PD, peritoneal dialysis.

Table 1. Comparisons of plasma FGF-23, $\mathrm{CA}^{2+}, \mathrm{P}^{3+}, \mathrm{CA}$ x P, and PTH levels between PD patients and healthy controls.

\begin{tabular}{lcc}
\hline & Healthy controls $(\mathrm{N}=25)$ & PD patients $(\mathrm{N}=62)$ \\
\hline FGF-23 $(\mathrm{ng} / \mathrm{L})$ & $34.4 \pm 12.2$ & $279.9 \pm 76.6^{*}$ \\
$\mathrm{Ca}^{2+}(\mathrm{mM})$ & $1.1 \pm 0.3$ & $1.9 \pm 0.8^{*}$ \\
$\mathrm{P}^{3+}(\mathrm{mM})$ & $2.4 \pm 0.3$ & $2.2 \pm 0.4^{*}$ \\
$\mathrm{Ca} \times \mathrm{P}\left(\mathrm{mg} / \mathrm{dL}^{2}\right)$ & $34.3 \pm 3.1$ & $58.0 \pm 10.8^{*}$ \\
$\mathrm{PTH}(\mathrm{pg} / \mathrm{mL})$ & $35.7 \pm 10.4$ & $441.5 \pm 293.7^{*}$ \\
\hline$* \mathrm{P}<0.05$, compared with healthy controls. FGF-23 = fibroblast growth factor- $23 ; \mathrm{Ca}^{2+}=$ calcium; $\mathrm{P}^{3+}=$ phosphorus; \\
$\mathrm{Ca} \times \mathrm{P}=$ calcium-phosphorus product; PTH = parathyroid hormone; $\mathrm{PD}=$ peritoneal dialysis.
\end{tabular}

According to the degree of elevated levels of plasma FGF-23, PD patients were divided into 3 groups: FGF-23 tertile $1(0-200 \mathrm{ng} / \mathrm{L})$, FGF-23 tertile $2(200-400 \mathrm{ng} / \mathrm{L})$, and FGF-23 tertile 3 (400-600 ng/L). The results showed that plasma $\mathrm{P}^{3+}$, Ca x P, and PTH levels of PD patients in FGF-23 tertile 3 were significantly higher than those in FGF-23 tertiles 1 and 2 (all $\mathrm{P}<0.05$ ). However, there was no statistically significant difference in plasma $\mathrm{Ca}^{2+}$ levels among the 3 groups (all $\mathrm{P}>0.05$; Table 2).

Table 2. Comparisons of plasma $\mathrm{CA}^{2+}, \mathrm{P}^{3+}, \mathrm{CA} x \mathrm{P}$, and PTH levels in different FGF-23 tertiles.

\begin{tabular}{lccc}
\hline & FGF-23 tertile $1(\mathrm{~N}=15)$ & FGF-23 tertile 2 $(\mathrm{N}=32)$ & FGF-23 tertile 3 $(\mathrm{N}=15)$ \\
\hline $\mathrm{Ca}^{2+}(\mathrm{mM})$ & $1.6 \pm 0.6$ & $1.9 \pm 0.7$ & $2.5 \pm 0.7^{\mathrm{a}, \mathrm{b}}$ \\
$\mathrm{P}^{3^{+}}(\mathrm{mM})$ & $2.1 \pm 0.4$ & $2.3 \pm 0.5$ & $2.3 \pm 0.3$ \\
$\mathrm{Ca} \times \mathrm{P}\left(\mathrm{mg}^{2} / \mathrm{dL}^{2}\right)$ & $49.5 \pm 6.7$ & $54.2 \pm 6.0$ & $68.1 \pm 9.1^{\mathrm{a}, \mathrm{b}}$ \\
$\mathrm{PTH}(\mathrm{pg} / \mathrm{mL})$ & $414.3 \pm 293.7$ & $434.8 \pm 219.5$ & $476.2 \pm 367.9^{\mathrm{a}, \mathrm{b}}$ \\
\hline
\end{tabular}

${ }^{\text {aP }}<0.05$, compared with FGF-23 tertile 1 ; ${ }^{\text {P }}<0.05$, compared with FGF-23 tertile 2 . FGF-23 = fibroblast growth factor-23; $\mathrm{Ca}^{2+}=$ calcium; $\mathrm{P}^{3+}=$ phosphorus; $\mathrm{Ca} \times \mathrm{P}=$ calcium-phosphorus product; $\mathrm{PTH}=$ parathyroid hormone. 


\section{Plasma FGF-23 levels in different CIMT tertiles}

According to CIMT tertiles, PD patients were classified into 3 groups: CIMT tertile 1 $(<0.7 \mathrm{~mm})$, CIMT tertile $2(0.7-1.0 \mathrm{~mm})$, and CIMT tertile $3(>1.0 \mathrm{~mm})$. There were significant differences in plasma FGF-23 levels among the 3 groups (all $\mathrm{P}<0.05$; Figure 2). The PD patients with CIMT $>1.0 \mathrm{~mm}$ showed the highest levels of FGF-23 (346.2 $\pm 59.0 \mathrm{ng} / \mathrm{L})$. However, there was no statistically significant difference in plasma $\mathrm{Ca}^{2+}, \mathrm{P}^{3+}, \mathrm{Ca} \times \mathrm{P}$, or PTH levels in the 3 groups (all $\mathrm{P}>0.05$; Table 3 ).

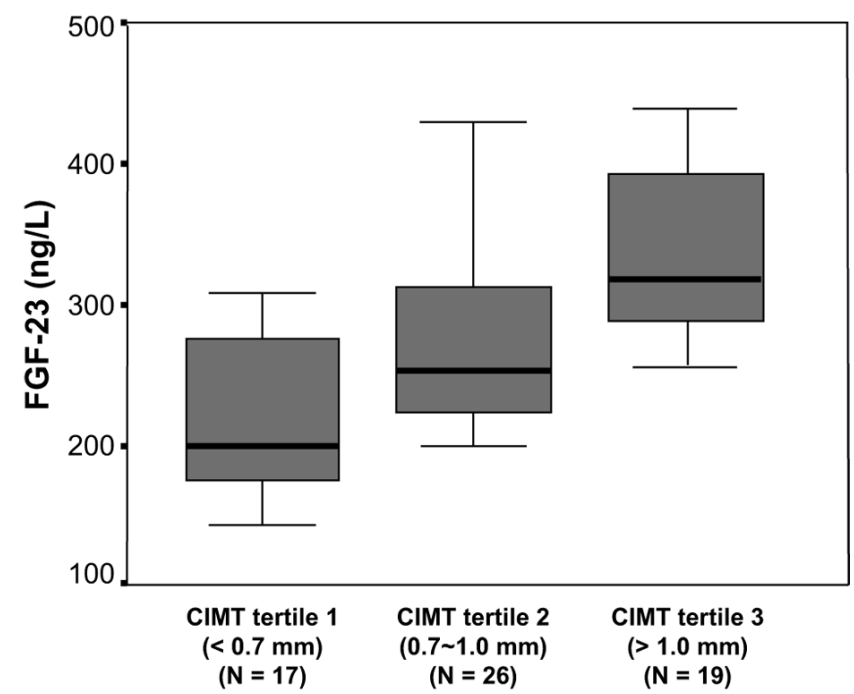

Figure 2. Plasma FGF-23 levels in different CIMT tertiles. FGF-23 = fibroblast growth factor-23; CIMT $=$ carotid artery intima-media thickness.

Table 3. Comparisons of plasma FGF-23, $\mathrm{CA}^{2+}, \mathrm{P}^{3+}, \mathrm{CA} \times \mathrm{P}$, and PTH levels in different CIMT tertiles.

\begin{tabular}{lccc}
\hline & CIMT tertile 1 $(\mathrm{N}=18)$ & CIMT tertile 2 $(\mathrm{N}=25)$ & CIMT tertile 3 $(\mathrm{N}=19)$ \\
\hline FGF-23 $(\mathrm{ng} / \mathrm{L})$ & $189.4 \pm 62.3$ & $261.4 \pm 56.8^{\mathrm{a}}$ & $346.2 \pm 59.0^{\mathrm{a}, \mathrm{b}}$ \\
$\mathrm{Ca}^{2+}(\mathrm{mM})$ & $1.6 \pm 0.7$ & $2.0 \pm 0.6$ & $2.3 \pm 0.9$ \\
$\mathrm{P}^{3+}(\mathrm{mM})$ & $2.1 \pm 0.4$ & $2.2 \pm 0.5$ & $2.2 \pm 0.4$ \\
$\mathrm{Ca} \times \mathrm{P}\left(\mathrm{mg} / \mathrm{dL}^{2}\right)$ & $58.6 \pm 8.2$ & $59.7 \pm 6.7$ & $62.1 \pm 6.1$ \\
$\mathrm{PTH}(\mathrm{pg} / \mathrm{mL})$ & $480.6 \pm 255.8$ & $495.2 \pm 315.9$ & $513.0 \pm 408.2$ \\
\hline
\end{tabular}

aP $<0.05$, compared with CIMT tertile 1 ; ${ }^{\mathrm{b}} \mathrm{P}<0.05$, compared with CIMT tertile $2 . \mathrm{FGF}-23=$ fibroblast growth factor-23; $\mathrm{Ca}^{2+}=$ calcium; $\mathrm{P}^{3+}=$ phosphorus; $\mathrm{Ca} \times \mathrm{P}=$ calcium-phosphorus product; $\mathrm{PTH}=$ parathyroid hormone; $\mathrm{CIMT}=$ carotid artery intima-media thickness.

\section{Plasma FGF-23 levels in PD patients with/without LVH}

Our results indicated that PD patients with LVH had higher levels of plasma FGF-23, $\mathrm{N}$-terminal pro-brain natriuretic peptide (NT-Pro-BNP), cardiac troponin I (cTnI), and $\mathrm{P}^{3+}$ than those without LVH (all $\mathrm{P}<0.05$; Figure 3 ). No significant difference in plasma myocardial performance index (MPI) levels was observed between PD patients with LVH and without LVH $(\mathrm{P}=0.122$; Table 4). 


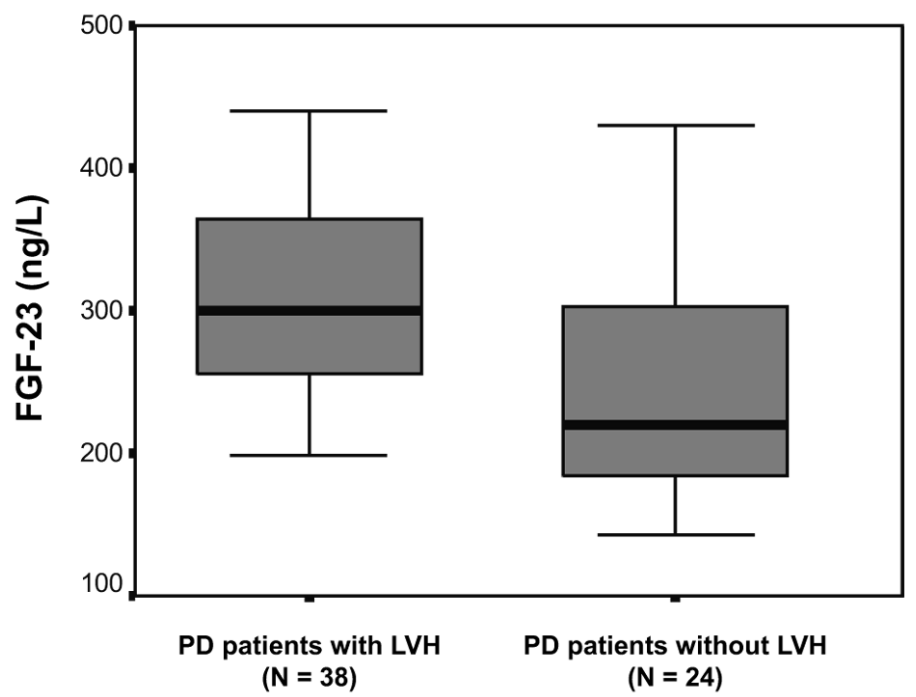

Figure 3. Comparisons of plasma FGF-23 levels between PD patients with LVH and without LVH. FGF-23 = fibroblast growth factor-23; $\mathrm{PD}=$ peritoneal dialysis; $\mathrm{LVH}=$ left ventricular hypertrophy.

Table 4. Comparisons of plasma FGF-23 levels in PD patients with/without LVH.

\begin{tabular}{lcc}
\hline & PD patients with LVH $(\mathrm{N}=15)$ & PD patients without $\mathrm{LVH}(\mathrm{N}=32)$ \\
\hline FGF-23 $(\mathrm{ng} / \mathrm{L})$ & $0.3 \pm 0.2$ & $198.4 \pm 68.8^{*}$ \\
MPI $(\mathrm{mM})$ & $0.5 \pm 0.2$ & $0.3 \pm 0.2$ \\
NTT-Pro-BNP $(\mathrm{pg} / \mathrm{mL})$ & $4015.3 \pm 3055.6$ & $3021.0 \pm 2388.7^{*}$ \\
CTnI $(\mathrm{ng} / \mathrm{mL})$ & $0.3 \pm 0.1$ & $0.1 \pm 0.1^{*}$ \\
$\mathrm{P}^{3+}(\mathrm{mM})$ & $2.5 \pm 0.8$ & $1.7 \pm 0.6^{*}$ \\
\hline
\end{tabular}

$* \mathrm{P}<0.05$, compared with $\mathrm{PD}$ patients without $\mathrm{LVH} . \mathrm{PD}=$ peritoneal dialysis; $\mathrm{LVH}=$ left ventricular hypertrophy; FGF-23 = fibroblast growth factor 23; MPI = myocardial performance index; NT-Pro-BNP = N-terminal pro-brain natriuretic peptide; $\mathrm{cTnI}=$ cardiac troponin $\mathrm{I} ; \mathrm{P}^{3+}=$ phosphorus.

\section{Correlation analyses}

The Pearson correlation analyses showed that plasma $\mathrm{P}^{3+}$, Ca x P, plasma PTH, CIMT, LVMI, and MPI levels were positively associated with plasma FGF-23 levels (all $\mathrm{P}<0.05$; Figure 4). Multiple-stepwise regression analysis also revealed that plasma $\mathrm{P}^{3+}$, plasma $\mathrm{PTH}$, CIMT, LVMI, and MPI levels were strongly associated with plasma FGF-23 levels (all $\mathrm{P}<$ $0.05)$. However, no similar correlations were observed in plasma NT-Pro-BNP and cTnI levels (both P > 0.05; Table 5).

\section{DISCUSSION}

The FGF family consists of 23 members (FGF-1-23); FGF-23 was originally identified as a novel member of this FGF family (Puhr et al., 2010) and is generally recognized as a bone-derived protein that is mainly secreted by osteoblasts and osteocytes in adults (Oikonomou et al., 2013). 

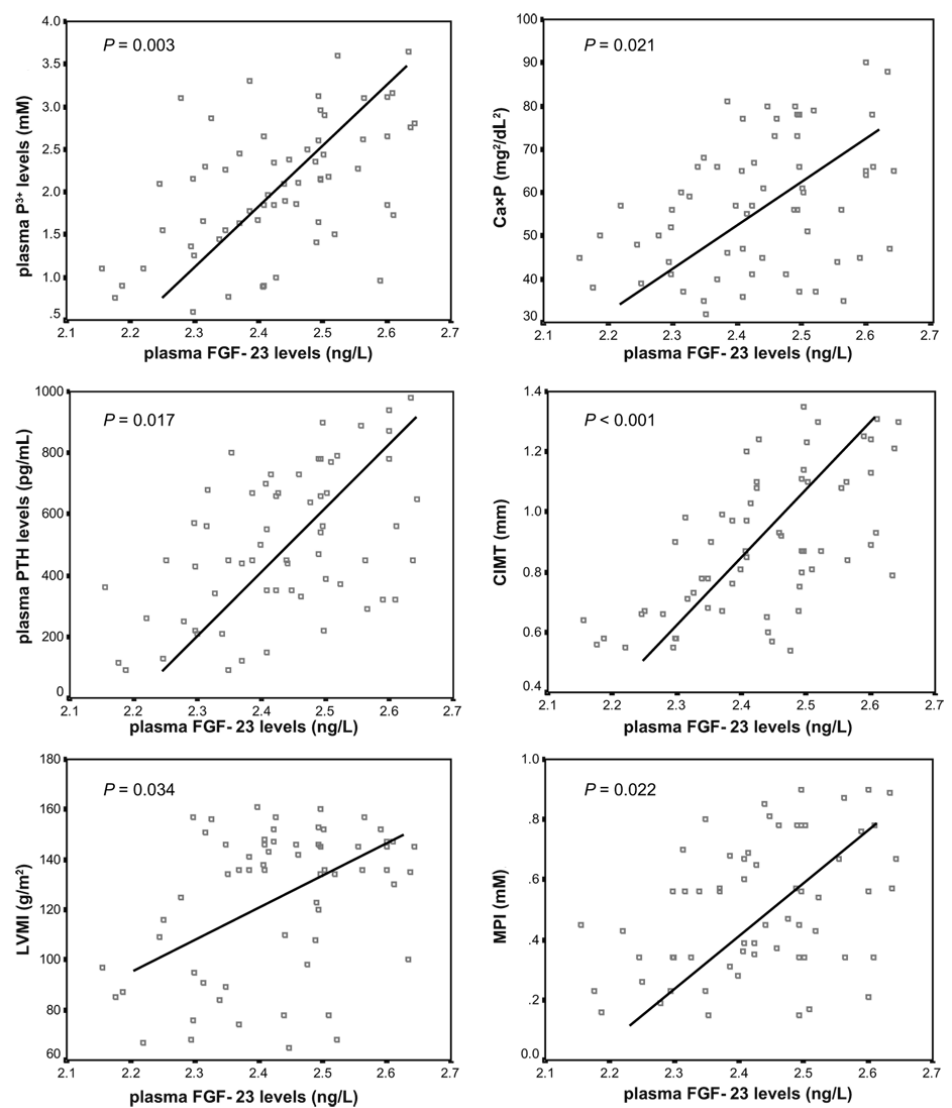

Figure 4. Correlation plots showing the relationships of plasma FGF-23 levels with plasma $\mathrm{P}^{3+}, \mathrm{Ca} \times \mathrm{P}$, plasma PTH, CIMT, LVMI, and MPI levels. FGF-23 = fibroblast growth factor-23; $\mathrm{P}^{3+}=$ phosphorus; $\mathrm{Ca} \times \mathrm{P}=$ calciumphosphorus product; $\mathrm{PTH}=$ parathyroid hormone; $\mathrm{CIMT}=$ carotid artery intima-media thickness; LVMI $=$ left ventricular mass index; MPI = myocardial performance index.

Table 5. Correlation analyses for the relationships of plasma FGF-23 levels with other indicators.

\begin{tabular}{|c|c|c|c|c|}
\hline & \multicolumn{2}{|c|}{ Univariate } & \multicolumn{2}{|c|}{ Multivariate } \\
\hline & $\mathrm{r}$ & $\mathrm{P}$ & $\beta$ & $\mathrm{P}$ \\
\hline $\mathrm{P}^{3+}(\mathrm{mM})$ & 0.519 & 0.003 & 0.491 & 0.001 \\
\hline $\mathrm{Ca}^{2+}(\mathrm{mM})$ & 0.256 & 0.095 & 0.374 & 0.895 \\
\hline $\mathrm{Ca} \times \mathrm{P}\left(\mathrm{mg}^{2} / \mathrm{dL}^{2}\right)$ & 0.374 & 0.021 & 0.422 & 0.068 \\
\hline PTH (pg/mL) & 0.512 & 0.017 & 0.487 & 0.024 \\
\hline CIMT (mm) & 0.628 & 0.000 & 0.685 & 0.001 \\
\hline $\operatorname{LVMI}\left(\mathrm{g} / \mathrm{m}^{2}\right)$ & 0.387 & 0.034 & 0.287 & 0.031 \\
\hline MPI (mM) & 0.409 & 0.022 & 0.301 & 0.026 \\
\hline NT-Pro-BNP (pg/mL) & -0.046 & 0.056 & -0.349 & 0.348 \\
\hline $\mathrm{cTnI}(\mathrm{ng} / \mathrm{mL})$ & -0.013 & 0.937 & 0.205 & 0.105 \\
\hline
\end{tabular}

FGF-23 = fibroblast growth factor-23; $\mathrm{P}^{3+}=$ phosphorus; $\mathrm{Ca}^{2+}=$ calcium; $\mathrm{Ca} \times \mathrm{P}=$ calcium-phosphorus product; $\mathrm{PTH}=$ parathyroid hormone; CIMT = carotid artery intima-media thickness; LVMI = left ventricular mass index; MPI = myocardial performance index; NT-Pro-BNP $=$ N-terminal pro-brain natriuretic peptide; $c$ TnI $=$ cardiac troponin I. 
It has been well-established that the function of FGF-23 is quite different from that of other members of the FGF family, as it can promote renal phosphate excretion by suppressing renal $\mathrm{Na} / \mathrm{Pi}$ co-transporter activity in the proximal tubule and inhibit conversion of 25-hydroxyvitamin D to the active 1,25(OH)2D form (Jüppner, 2011). In addition, FGF-23 may regulate the levels of hyperphosphatemia, serum $\mathrm{PTH}$, and 1,25(OH)2D3 (Bergwitz and Jüppner, 2010). Several recent studies have found that patients with chronic renal failure are at high risk of developing atherosclerotic cardiovascular disease (Fox et al., 2010; Amabile et al., 2012). Moreover, FGF-23 is independently associated with several cardiovascular risk factors, such as endothelial dysfunction, arterial stiffness, and total body atherosclerosis in cardiovascular diseases (Mirza et al., 2009a; Balci et al., 2010). It has been speculated that a subtle relationship exists between FGF-23 and the pathogenesis of atherosclerosis; however, the exact mechanism is unclear. Abundant evidence has shown that cardiovascular disease is positively correlated with calcium and phosphorus metabolism, cholesterol and non-highdensity lipoprotein levels, and the relationship between plasma FGF-23 and $\mathrm{P}^{3+}$; thus, plasma FGF-23 is likely associated with the incidence of atherosclerosis in PD patients (Peacock, 2010; Bernstein et al., 2012; Asicioglu et al., 2013). In contrast, LVH and left ventricular dilatation are reversible determinants of death from cardiovascular disease, and MPI is a new index for evaluating cardiac function (Verdecchia et al., 2009; Carluccio et al., 2012). Previous studies indicate that LVMI and MPI may be linked to FGF-23 (Kirkpantur et al., 2011). Thus, FGF-23 levels may also affect cardiac structures and functions, as FGF-23 may be correlated with cardiovascular disease in PD patients (Kendrick et al., 2011; Isakova et al., 2013). However, the above indicator has not been reported for plasma FGF-23 in PD patients.

In the present study, we evaluated the exact role of FGF-23 in the pathogenesis of atherosclerosis in PD patients. Our results indicated that plasma FGF-23 levels in PD patients were significantly higher than those of control subjects, indicating that the kidney may be the major organ of FGF-23 metabolism and that FGF-23 may be involved in PD progression. This may be because FGF-23 is often highly bound to some proteins and converted into metabolites in vivo; as a result, FGF-23 cannot be filtered through a dialysis membrane, leading to high levels of plasma FGF-23 in PD patients (Seiler et al., 2010). Furthermore, we found a positive correlation between plasma FGF-23 levels and plasma $\mathrm{P}^{3+}$, plasma PTH, CIMT, LVMI, and MPI levels, suggesting that FGF-23 may be involved in mineral metabolism in the kidney. FGF-23 decreases serum 1,25(OH)2D3 concentration and reduces the reabsorption of phosphate, ultimately increasing renal excretion of plasma $\mathrm{P}^{3+}$. In addition, inhibition of FGF-23 expression may contribute to the increase in active vitamin D absorption, thereby regulating the concentration of plasma $\mathrm{P}^{3+}$. Thus, stable plasma $\mathrm{P}^{3+}$ levels are maintained by FGF-23 (Srivaths et al., 2011). Significantly positive correlations between plasma FGF-23 levels and plasma $\mathrm{P}^{3+}$, plasma PTH, CIMT, LVMI, and MPI levels were also observed in multiple-stepwise regression analyses, suggesting that FGF-23 plays an important role in the development and progression of atherosclerosis in PD patients. A reasonable explanation for this phenomenon is that FGF-23 may cause thickening and fibrosis of the carotid intima by binding to its receptor (Kendrick et al., 2011). It is widely accepted that FGFR1 and FGFR4 are receptors for FGF-23, which are present in myocardial cells and the vascular membrane of the coronary vessels and veins. Binding of FGFR1 and FGFR4 are activated upon binding to FGF-23, causing cardiac hypertrophy and fibrosis; thus, FGF-23 may play a crucial role in changes in cardiac structure and function in PD patients (Gutiérrez et al., 2009).

In conclusion, our findings indicate that plasma FGF-23 levels may play an important 
role in the initiation and progression of atherosclerosis. Thus, detection of plasma FGF-23 levels may be a promising biomarker for the early detection of atherosclerosis in PD patients.

\section{Conflicts of interest}

The authors declare no conflict of interest.

\section{ACKNOWLEDGMENTS}

We would like to acknowledge the reviewers for their helpful comments on this paper.

\section{REFERENCES}

Amabile N, Guérin AP, Tedgui A, Boulanger CM, et al. (2012). Predictive value of circulating endothelial microparticles for cardiovascular mortality in end-stage renal failure: a pilot study. Nephrol. Dial. Transplant. 27: 1873-1880.

Ashikaga E, Honda H, Suzuki H, Hosaka N, et al. (2010). Impact of fibroblast growth factor 23 on lipids and atherosclerosis in hemodialysis patients. Ther. Apher. Dial. 14: 315-322.

Asicioglu E, Kahveci A, Arikan H, Koc M, et al. (2013). Fibroblast growth factor-23 levels are associated with vascular calcifications in peritoneal dialysis patients. Nephron Clin. Pract. 124: 89-93.

Balci M, Kirkpantur A, Gulbay M and Gurbuz OA (2010). Plasma fibroblast growth factor-23 levels are independently associated with carotid artery atherosclerosis in maintenance hemodialysis patients. Hemodial. Int. 14: 425-432.

Bergwitz C and Jüppner H (2010). Regulation of phosphate homeostasis by PTH, vitamin D, and FGF23. Annu. Rev. Med. 61: 91-104.

Bernstein AM, Ding EL, Willett WC and Rimm EB (2012). A meta-analysis shows that docosahexaenoic acid from algal oil reduces serum triglycerides and increases HDL-cholesterol and LDL-cholesterol in persons without coronary heart disease. J. Nutr. 142: 99-104.

Boudville N, Kemp A, Clayton P, Lim W, et al. (2012). Recent peritonitis associates with mortality among patients treated with peritoneal dialysis. J. Am. Soc. Nephrol. 23: 1398-1405.

Carluccio E, Biagioli P, Alunni G, Murrone A, et al. (2012). Improvement of myocardial performance (Tei) index closely reflects intrinsic improvement of cardiac function: assessment in revascularized hibernating myocardium. Echocardiography 29: 298-306.

Carrero JJ, de Jager DJ, Verduijn M, Ravani P, et al. (2011). Cardiovascular and noncardiovascular mortality among men and women starting dialysis. Clin. J. Am. Soc. Nephrol. 6: 1722-1730.

Devereux B, Alonso DR, Lutas EM, Gottlieb GJ, et al. (1986). Echocardiographic assessment of left ventricular hypertrophy: comparison to necropsy findings. Am. J. Cardiol. 57: 450-458.

Fox CS, Muntner P, Chen AY, Alexander KP, et al. (2010). Use of evidence-based therapies in short-term outcomes of ST-segment elevation myocardial infarction and non-ST-segment elevation myocardial infarction in patients with chronic kidney disease: a report from the National Cardiovascular Data Acute Coronary Treatment and Intervention Outcomes Network registry. Circulation 121: 357-365.

Gutiérrez OM, Januzzi JL, Isakova T, Laliberte K, et al. (2009). Fibroblast growth factor 23 and left ventricular hypertrophy in chronic kidney disease. Circulation 119: 2545-2552.

Hernandez GT, Sippel M and Mukherjee D (2013). Interrelationship between chronic kidney disease and risk of cardiovascular diseases. Cardiovasc. Hematol. Agents Med. Chem. 11: 38-43.

Isakova T, Houston J, Santacruz L, Schiavenato E, et al. (2013). Associations between fibroblast growth factor 23 and cardiac characteristics in pediatric heart failure. Pediatr. Nephrol. 28: 2035-2042.

Jüppner H (2011). Phosphate and FGF-23. Kidney Int. Suppl. 79 (Suppl 121): S24-S27.

Kendrick J, Cheung AK, Kaufman JS, Greene T, et al. (2011). FGF-23 associates with death, cardiovascular events, and initiation of chronic dialysis. J. Am. Soc. Nephrol. 22: 1913-1922.

Kirkpantur A, Balci M, Gurbuz OA, Afsar B, et al. (2011). Serum fibroblast growth factor-23 (FGF-23) levels are independently associated with left ventricular mass and myocardial performance index in maintenance haemodialysis patients. Nephrol. Dial. Transplant. 26: 1346-1354.

Lim WH, Boudville N, McDonald SP, Gorham G, et al. (2011). Remote indigenous peritoneal dialysis patients have higher risk of peritonitis, technique failure, all-cause and peritonitis-related mortality. Nephrol. Dial. Transplant. 
26: 3366-3372.

Mailliez S, Shahapuni I, Lecaque C, Massy ZA, et al. (2008). Vitamin D levels and early mortality among incident hemodialysis patients. Kidney Int. 74: 389.

Malík J, Tuka V, Mokrejsová M, Holaj R, et al. (2009). Mechanisms of chronic heart failure development in end-stage renal disease patients on chronic hemodialysis. Physiol. Res. 58: 613-621.

Mehrotra R, Kermah DA, Salusky IB, Wolf MS, et al. (2009). Chronic kidney disease, hypovitaminosis D, and mortality in the United States. Kidney Int. 76: 977-983.

Mehrotra R, Chiu YW, Kalantar-Zadeh K, Bargman J, et al. (2011). Similar outcomes with hemodialysis and peritoneal dialysis in patients with end-stage renal disease. Arch. Intern. Med. 171: 110-118.

Mirza MA, Hansen T, Johansson L, Ahlstrom H, et al. (2009a). Relationship between circulating FGF23 and total body atherosclerosis in the community. Nephrol. Dial. Transplant. 24: 3125-3131.

Mirza MA, Larsson A, Lind L and Larsson TE (2009b). Circulating fibroblast growth factor-23 is associated with vascular dysfunction in the community. Atherosclerosis 205: 385-390.

Oh KH, Hwang YH, Cho JH, Kim M, et al. (2012). Outcome of early initiation of peritoneal dialysis in patients with endstage renal failure. J. Korean Med. Sci. 27: 170-176.

Oikonomou KA, Orfanidou TI, Vlychou MK, Kapsoritakis AN, et al. (2013). Lower fibroblast growth factor 23 levels in young adults with Crohn disease as a possible secondary compensatory effect on the disturbance of bone and mineral metabolism. J. Clin. Densitom. 17: 177-184.

Peacock M (2010). Calcium metabolism in health and disease. Clin. J. Am. Soc. Nephrol. 5 (Suppl 1): S23-S30.

Prié D, Ureña Torres P and Friedlander G (2009). Latest findings in phosphate homeostasis. Kidney Int. 75: 882-889.

Puhr M, Santer FR, Neuwirt H, Marcias G, et al. (2010). SOCS-3 antagonises the proliferative and migratory effects of fibroblast growth factor-2 in prostate cancer by inhibition of p44/p42 MAPK signalling. Endocr. Relat. Cancer 17: 525-538.

Razzaque MS and Lanske B (2007). The emerging role of the fibroblast growth factor-23-klotho axis in renal regulation of phosphate homeostasis. J. Endocrinol. 194: 1-10.

Seiler S, Reichart B, Roth D, Seibert E, et al. (2010). FGF-23 and future cardiovascular events in patients with chronic kidney disease before initiation of dialysis treatment. Nephrol. Dial. Transplant. 25: 3983-3989.

Shimada T, Urakawa I, Isakova T, Yamazaki Y, et al. (2010). Circulating fibroblast growth factor 23 in patients with end-stage renal disease treated by peritoneal dialysis is intact and biologically active. J. Clin. Endocrinol. Metab. 95: 578-585.

Sinnakirouchenan R and Holley JL (2011). Peritoneal dialysis versus hemodialysis: risks, benefits, and access issues. $A d v$. Chronic Kidney Dis. 18: 428-432.

Srivaths PR, Goldstein SL, Silverstein DM, Krishnamurthy R, et al. (2011). Elevated FGF 23 and phosphorus are associated with coronary calcification in hemodialysis patients. Pediatr. Nephrol. 26: 945-951.

Verdecchia P, Sleight P, Mancia G, Fagard R, et al. (2009). Effects of telmisartan, ramipril, and their combination on left ventricular hypertrophy in individuals at high vascular risk in the Ongoing Telmisartan Alone and in Combination with Ramipril Global End Point Trial and the Telmisartan Randomized Assessment Study in ACE Intolerant Subjects with Cardiovascular Disease. Circulation 120: 1380-1389.

Wald R, Sarnak MJ, Tighiouart H, Cheung AK, et al. (2008). Disordered mineral metabolism in hemodialysis patients: an analysis of cumulative effects in the Hemodialysis (HEMO) Study. Am. J. Kidney Dis. 52: 531-540.

Webster AL, Yan MS and Marsden PA (2013). Epigenetics and cardiovascular disease. Can. J. Cardiol. 29: 46-57. 